\title{
AGENDA GOVERNAMENTAL BRASILEIRA: UMA ANÁLISE DA CAPACIDADE E DIVERSIDADE NAS PRIORIDADES EM POLÍTICAS PÚBLICAS NO PERÍODO DE 2003 A 2014
}

\author{
THE BRAZILIAN POLICY AGENDAS: \\ AN ANALYSIS OF CAPACITY AND DIVERSITY OVER PRIORITIES IN PUBLIC POLICIES FOR THE PERIOD 2003 TO 2014 \\ AGENDA GUBERNAMENTAL BRASILEÑA: \\ UN ANÁLISIS DE LA CAPACIDAD Y DIVERSIDAD EN LAS PRIORIDADES EN POLÍTICAS PÚBLICAS EN EL PERÍODO DE \\ 2003 A 2014
}

\section{RESUMO}

0 presente trabalho tem como objetivo apresentar os primeiros resultados da pesquisa conduzida pelo Laboratório de Agenda Governamental no Brasil. Os resultados a serem apresentados e discutidos no trabalho focalizam análises sobre a capacidade e a diversidade da atenção presidencial sobre políticas públicas em três períodos de governo: primeiro e segundo governos Lula e o primeiro governo Dilma. As análises e conclusões corroboram os preceitos teóricos dos estudos de agenda-setting que evidenciam manutenções e mudanças em prioridades de políticas públicas, ou seja, momentos incrementais e momentos de mudança na agenda. Apontam, ainda, para movimentações decisivas na capacidade, diversidade e elasticidade da agenda governamental, causadas, sobretudo, por distintos momentos de fricção institucional e cognitiva nos ambientes doméstico e externo. Demonstram, por fim, que as variações ocorridas nas prioridades da presidência vão muito além de mudanças macrossistêmicas consequentes de alterações partidárias e/ou de caráter partidário-ideológico. Mudanças em prioridades governamentais podem acontecer e, de fato, ocorrem, dentro dos próprios governos e em governos do mesmo partido.

PALAVRAS-CHAVE: Políticas públicas, dinâmica de políticas, atenção governamental, agenda-setting, mensagens ao Congresso Nacional.

Felipe Gonçalves Brasil ${ }^{12}$

fbrasil.pp@gmail.com

ORCID: 0000-0001-7282-0110

Ana Claudia Niedhardt Capella ${ }^{34}$

acapella@terra.com.br

ORCID: 0000-0002-1423-898X

1 Universidade Estadual Paulista Júlio de Mesquita Filho, Faculdade de Ciências e Letras, Araraquara, SP, Brasil

2 The University of Texas, Department of Government, Austin, TX, United States of America

${ }^{3}$ Universidade Estadual Paulista Júlio de Mesquita Filho, Faculdade de Ciências e Letras, Araraquara, SP, Brasil

${ }^{4}$ Universidade Federal de São Carlos, Programa de Pós-graduação em Ciência Política, São Carlos, SP, Brasil

Submetido 10.09.2018. Aprovado 11.04.2019

Avaliado pelo processo de double blind review

DOI: http://dx.doi.org/10.12660/cgpc.v24n78.76950

Esta obra está submetida a uma licença Creative Commons 
Felipe Gonçalves Brasil - Ana Claudia Niedhardt Capella

\begin{abstract}
This paper aims to present the first results of the research conducted by the Brazilian Policy Agendas Project. The results to be presented and discussed in the paper focus on analyses of the capacity and diversity of presidential attention to public policies in three periods of government: first and second Lula government and Dilma government. The analyses and conclusions corroborate the important theoretical precepts of the agenda-setting studies that evidence maintenance and changes in public policy priorities, that is, incremental moments and moments of change in the agenda. They also point to important movements in the capacity, diversity and elasticity of the governmental agenda, caused, above all, by different moments of institutional and cognitive friction in the domestic and external environments. They show, finally, that variations in the presidency's priorities go far beyond macro systemic changes resulting from partisan and party-ideological changes. Changes in government priorities can and do occur even within the same governments and governments of the same party.
\end{abstract}

KEYWORDS: Public policies, policy dynamics, government attention, agenda-setting, messages to the Nacional Congress.

\title{
RESUMEN
}

El presente documento tiene como objetivo presentar los primeros resultados de la investigación conducida por el Laboratorio de Agenda Gubernamental en Brasil. Los resultados que se van a presentar y discutir en el trabajo enfocan el análisis sobre la capacidad y la diversidad de la atención presidencial sobre políticas públicas en tres períodos de gobierno: primero y segundo gobierno de Lula y el gobierno de Dilma. Los análisis y conclusiones corroboran con preceptos teóricos importantes de los estudios de agenda-setting que evidencian mantenimientos y cambios de prioridades de politicas públicas, o sea, momentos incrementales y momentos de cambio en la agenda. Señalan también importantes cambios en la capacidad, la diversidad y la elasticidad de la agenda del gobierno causados principalmente por la existencia de distintos momentos de fricción institucional y cognitiva en los ambientes internos y externos. Demuestran, por fin, que las variaciones ocurridas en las prioridades de la presidencia van mucho más allá de cambios macrosistémicos consecuentes de alteraciones partidistas y de carácter partidista-ideológicos. Los cambios en las prioridades gubernamentales pueden ocurrir y, de hecho, ocurren, incluso dentro de los mismos gobiernos y de gobiernos del mismo partido.

PALABRAS CLAVE: Políticas públicas, dinámica de políticas, atención gubernamental, agenda-setting, mensaje al Congreso Nacional

\section{INTRODUÇÃO}

A literatura internacional sobre a formação da agenda governamental pode ser classificada em quatro momentos principais ( $\mathrm{Ca}-$ pella \& Brasil, 2015). O primeiro momento (anos 1970) é marcado pelo trabalho de Cobb e Elder (1971), que procuraram explicar como as demandas originadas na sociedade (ou no interior do próprio Estado) são filtradas pelos tomadores de decisão, que acabam priorizando algumas questões em detrimento de outras. O segundo momento (anos 1980-1990) é marcado pelo surgimento de modelos teóricos que deslocaram o foco para a investigação das intrincadas relações entre diferentes variáveis explicativas para a formação da agenda governamental. O modelo de Múltiplos Fluxos de John Kingdon $(1984,2003)$ e o modelo de
Equilíbrio Pontuado de Baumgartner e Jones (1993) surgem, então, como as principais inovações teóricas e metodológicas nos estudos da formação da agenda governamental. O terceiro momento (anos 2000) é marcado pela difusão desses modelos teóricos e sua aplicação em diversos estudos de caso, em diferentes contextos nacionais. O quarto e mais recente movimento da literatura tem focalizado o estudo das agendas em perspectiva comparada. As investigações sobre formação de agenda têm se dedicado a identificar mudanças na atenção governamental - ou seja, movimentações na agenda - em torno de diferentes políticas públicas, durante longos períodos e em diferentes sistemas políticos. Esse esforço enfrenta uma série de desafios e tem produzido um rico debate na literatura internacional, envolvendo a definição de indicadores de atenção gover- 
namental válidos para os diversos contextos político-institucionais, o desenvolvimento de categorias válidas do ponto de vista comparativo, testes de resultados, entre outras questões de ordem teórico-metodológica.

Como resultado dos primeiros esforços em aplicar essa literatura para explicar e entender a formação da agenda da presidência da República no Brasil, este trabalho tem como principal objetivo analisar a capacidade e a diversidade da agenda governamental brasileira entre os anos de 2003 e 2014. Para tanto, pretendemos analisar a composição das prioridades dos presidentes Lula e Dilma, e também entender como fatores internos e externos atuam em mudanças ou manutenções dessas prioridades. Assim, perguntamos: Quais temas prioritários foram abordados por esses presidentes? Quão ampla e diversa foi a agenda dos governos do PT à frente da presidência da República? De que forma períodos de sucessão eleitoral, crises econômicas internacionais, momentos de instabilidade política e econômica podem ser identificados como fatores importantes para a mudança das prioridades dos presidentes? Essas são algumas das questões que este artigo traz para o debate sobre a agenda governamental brasileira.

O artigo está estruturado em cinco seções, além desta introdução e das considerações finais. Na primeira parte, são retomadas as principais referências teóricas que norteiam os estudos de agenda-setting, com destaque para os desenvolvimentos mais recentes. Na segunda seção, são apresentadas algumas questões relacionadas ao escopo metodológico dos estudos sobre agenda, enfatizando aspectos enfrentados pelos estudiosos na literatura internacional e os procedimentos adotados na pesquisa conduzida no Brasil. Na terceira, focalizamos o indicador de atenção selecionado para o presente estudo - 0 documento Mensagem ao Congresso Nacional - desenvolvendo algumas considerações sobre esse documento e sobre a forma de análise empregada. A seguir, na quarta seção, apresentamos os conceitos de capacidade, diversidade e elasticidade da agenda e sua importância para a compreensão das mudanças e manutenções de prioridades da presidência, foco principal deste artigo. Por fim, a quinta e última seção apresenta os principais resultados da análise, apontando mudanças e continuidades na capacidade e diversidade de atenção sobre as políticas específicas ao longo do período.

\section{O PERCURSO TEÓRICO: POR QUE E PARA QUE ESTUDAR A FORMAÇÃO DA AGENDA?}

A formação da agenda governamental - entendida como o conjunto de questões sobre as quais o governo e pessoas ligadas a ele concentram sua atenção num determinado momento (Kingdon, 2003, p. 3) - é um dos aspectos centrais do processo de produção de políticas públicas. Considerando que a atenção é um recurso escasso (Jones \& Baumgartner, 2005) e que tanto pessoas quanto organizações estabelecem prioridades de atuação, estudar agenda significa identificar como o governo distribui atenção entre as diversas questões existentes, decidindo o que é um problema a ser priorizado (Baumgartner \& Jones, 2015). Entender de que forma alguns problemas são entendidos como mais importantes do que outros em um determinado momento, mobilizando a ação governamental, é precisamente o pon- 
Felipe Gonçalves Brasil - Ana Claudia Niedhardt Capella

to central dos estudos de agenda (Zahariadis, 2016).

Os estudos sobre agenda vêm se consolidando na literatura internacional desde os anos 1970. O estudo pioneiro realizado por Roger Cobb e Charles Elder (1971, 1972) inaugura as preocupações com o tema, diferenciando distintas dimensões da agenda. Partindo de entendimento semelhante ao de Cobb e Elder, Kingdon (2003) amplia o conjunto de atores relacionados à definição da agenda, considerando não apenas os tomadores de decisão dentro do Estado, mas também indivíduos e grupos ligados a eles. O modelo de Múltiplos Fluxos, proposto pelo autor, busca analisar a formulação de políticas públicas por meio de três fluxos (problemas, soluções e contexto político) eventualmente conectados por um empreendedor de políticas públicas que atua em momentos em que janelas de oportunidade tornam viáveis mudanças na agenda governamental e na agenda decisória (Capella, 2007; Kingdon, 2003; Zahariadis, 2014).

Mais tarde, Frank Baumgartner e Bryan Jones (1993) desenvolvem um modelo teórico dedicado a explicar como as agendas passam por períodos prolongados de estabilidade e também por processos de rápidas $\mathrm{e}$ abruptas mudanças. O modelo do Equilíbrio Pontuado proposto pelos autores baseia sua explicação para a mudança na agenda na dinâmica de funcionamento dos monopólios de políticas - estruturas institucionais capazes de manter o equilíbrio e inibir mudanças por longos períodos (feedback negativo). Por outro lado, quando esses mesmos monopólios se desestruturam, abrindo espaço para novos entendimentos e atores, observam-se mudanças rápidas na agenda (feedback positivo) (Baumgartner \& Jones, 1993; True, Jones, \& Baumgartner, 1999). O processamento de informação é definido como "coleta, montagem, interpretação e priorização dos sinais do ambiente" (Jones \& Baumgartner, 2005, p. 7) e está relacionado com o aumento (ou diminuição) da atenção dos policymakers em relação a uma política $\mathrm{e}$, consequentemente, com as mudanças na agenda. A forma como essa atenção seletiva se processa, concentrando a atenção em algumas questões, é a chave para a explicação das pontuações no sistema político. Assim, os autores passaram de um modelo de Equilíbrio Pontuado, que propunha explicações para as mudanças verificadas nos monopólios de políticas vinculados aos casos estudados (Baumgartner \& Jones, 1993), para uma tese geral sobre a pontuação (general punctuation thesis) (Jones \& Baumgartner, 2005), uma abordagem mais geral que destaca o papel do processamento de informações no sistema político como um todo.

A análise amplia-se, dos estudos originalmente concentrados nos Estados Unidos, para diversos contextos nacionais, permitindo não apenas a investigação sobre mudanças na agenda nesses países, mas também a realização de estudos comparados, ampliando a compreensão sobre os limites e possibilidades das teorias sobre agenda e mudança em políticas públicas em diversos países (Baumgartner, Green-Pedersen, \& Jones, 2006; Baumgartner, Jones, \& Mortensen, 2014; Baumgartner, Jones, \& Wilkerson, 2011). Esses estudos têm apontado para a viabilidade das explicações sobre estabilidade e mudança em políticas públicas baseadas nas formulações de Baumgartner e Jones (1993, 2002, 2015; Jones \& Baumgartner, 2005) em diferentes sistemas polí- 
ticos. Apesar das diferenças institucionais, verificaram-se dinâmicas de mudanças em políticas públicas com as características pontuações em vários países (Baumgartner et al., 2014; Brasil, 2017). Esse novo momento dos estudos de agenda-setting no campo de Políticas Públicas, envolvendo a análise comparada das agendas de diferentes países, ainda está em desenvolvimento e enfrenta uma série de desafios que envolvem questões metodológicas (ligadas à definição de variáveis comuns aos diversos contextos políticos-institucionais, o desenvolvimento de categorias válidas do ponto de vista comparativo, testes de resultados, entre outras questões) (Brasil, 2017; Capella, Brasil, \& Sudano, 2015). Apesar desses desafios, as pesquisas têm mostrado que o arcabouço teórico e metodológico desenvolvido com base nas formulações de Baumgartner e Jones é aplicável a qualquer sistema político e que permite a comparação entre agendas de diferentes países (John, 2006).

\section{O PERCURSO METODOLÓGICO: COMO ESTUDAR A FORMAÇÃO DA AGENDA?}

Do ponto de vista metodológico, Baumgartner e Jones (1993) propõem um desenho de pesquisa capaz de combinar dois tipos de estudos: os estudos longitudinais, que investigam uma única questão em seus vários estágios de desenvolvimento ao longo do tempo, adequados para analisar a entrada e saída de temas da agenda, mas dificilmente passíveis de generalização ou de comparação; e o segundo tipo, os estudos transversais (cross-sectional), que buscam analisar várias questões em um único momento, permitindo o desenvolvimento de explicações sobre o porquê de algumas questões atingirem um alto nível de atenção na agenda, en- quanto outras permanecem fora da atenção. Para os autores, ambas as perspectivas são importantes e é possível combiná-las (Baumgartner \& Jones, 1993, p. 47). Para desenvolver uma abordagem que combine os dois tipos de estudo, os autores buscaram identificar um conjunto de indicadores que pudessem permitir a observação e comparação entre diferentes casos, ao longo de um período prolongado. Foram consideradas, na versão inicial do modelo de Equilíbrio Pontuado, as seguintes fontes de dados para a investigação da agenda: audiências públicas para análise da atenção do Congresso em torno de cada questão; cobertura midiática para a compreensão do contexto em torno de uma questão que chega à agenda; e, em alguns casos, dados da opinião pública sobre diferentes questões. Para a análise desses dados, os autores aplicaram uma metodologia baseada em técnicas de análise de conteúdo que permitiu estudar grandes porções de materiais textuais (Baumgartner, Jones, \& Macleod, 1998, p. 2). Além da organização dos dados em quadros, os autores apoiaram-se em análises de regressão para observar a dinâmica de mudança na agenda. Assim, os autores conseguiram analisar estabilidade e mudanças na agenda para questões em particular, como energia nuclear, fumo e tabaco, pesticidas, entre outras, considerando períodos relativamente prolongados.

Para a estruturação da pesquisa no Brasil, foram definidos inicialmente três conjuntos de dados, vinculados aos Poderes Executivo, Legislativo e mídia, sendo a análise restrita ao período de 2003 a 2014 (Capella et al., 2015). Com foco no Poder Executivo, as Mensagens ao Congresso sinalizam prioridades em políticas, conforme detalharemos 
Felipe Gonçalves Brasil - Ana Claudia Niedhardt Capella

na próxima seção. Este trabalho debruça-se num recorte que considera os 12 documentos anuais referentes às Mensagens ao Congresso Nacional e que, ao todo, somam 1.686 dados.

\section{MENSAGENS AO CONGRESSO COMO INDICADOR DA ATENÇÃO PRESIDEN- CIAL}

Considerando que o presidente é um ator central ao processo de agenda-setting (Baumgartner \& Jones, 1993; Kingdon, 2003), a análise do conteúdo de suas mensagens consiste em um dos indicadores mais utilizados pela literatura na investigação da agenda. Baumgartner e Jones (1993) tomam como indicadores de atenção presidencial os discursos sobre "o Estado da Nação" (Presidential State of the Union Speeches), discursos anuais proferidos pelo presidente ao Congresso daquele país. Observando o conjunto de elementos que poderiam indicar níveis de atenção presidencial no Brasil, buscamos identificar um documento capaz de: a) traduzir as prioridades do presidente para um determinado período; b) ter periodicidade de publicação, sendo editado de maneira sistemática e frequente, para permitir comparações ao longo do tempo. O documento Mensagem ao Congresso Nacional resulta da exigência constitucional que determina que o presidente da República encaminhe, na abertura da sessão legislativa do Congresso Nacional, documento contendo mensagem e plano de governo "expondo a situação do País e solicitando as providências que julgar necessárias" (CF88, artigo 84, XI).

Em sua íntegra, o documento é composto por uma apresentação e um conjunto de capítulos nos quais são relatadas ações relacionadas aos grandes temas de interesse nacional. A apresentação é a parte introdutória, geralmente lida por ocasião da abertura dos trabalhos do Congresso Nacional, e contém menções a políticas públicas específicas e reflexões sobre o País, sintetizando o conjunto do documento e destacando os desafios e prioridades para o ano. A Mensagem ao Congresso tem sido entendida como documento que corresponde ao discurso presidencial anual (state of the union) praticado em diversos países, conforme investigação sobre o papel dos presidentes na atividade legislativa em países da América Latina elaborado por Arnold, Doyle e Wiesehomeier (2017). Portanto entendemos que, em um contexto marcado por atenção escassa, esses foram os temas considerados mais importantes pelo presidente naquele momento, pois foram selecionados para integrar seu discurso perante o Legislativo.

Para preparar a análise do documento, 0 texto foi dividido em sentenças. Estas foram subdivididas em fragmentos, considerando-se a menção a uma política pública específica como parâmetro. Por exemplo, a sentença "As nossas prioridades em 2004 são a geração de emprego e os investimentos na área social e de infra-estrutura" foi desmembrada em três fragmentos: o primeiro é "As nossas prioridades em 2004 são a geração de emprego", pois menciona-se política de emprego; o segundo é "e os investimentos na área social", uma vez que se destacam políticas sociais; e, por fim, "e de infra-estrutura", já que esse trecho destaca política de infra-estrutura.

O processo de codificação baseou-se na estrutura de códigos (codebook) que apresen- 
ta 19 códigos ou variaveis. Nessa estrutura, cada código representa uma política setorial distinta, conforme Quadro 1. Nossa análise, portanto, será concentrada nos códigos de Quadro 1. Macrocódigos de Políticas Setoriais acordo com o quadro abaixo utilizada para codificação das 1686 sentenças extraídas dos textos introdutórios das Mensagens ao Congresso Nacional.

\begin{tabular}{|c|c|}
\hline \multicolumn{2}{|c|}{ CÓDIGOS E POLÍTICAS SETORIAIS } \\
\hline 1 - MACROECONOMIA & 12 - JUSTIÇA E ADMINISTRAÇÃO \\
\hline & INTERNA \\
\hline 2 - DIREITOS CIVIS, DIREITOS DAS & 13 - POLÍTICAS SOCIAIS \\
\hline \multicolumn{2}{|l|}{ MINORIAS E LIBERADE } \\
\hline \multirow[t]{2}{*}{3 - SAÚDE } & 14 - DESENVOLVIMENTO LOCAL E \\
\hline & HABITAÇÃO \\
\hline \multirow[t]{2}{*}{4 - AGRICULTURA, PECUÁRIA E PESCA } & 15 - SETOR FINANCEIRO, INDÚSTRIA E \\
\hline & COMÉRCIO \\
\hline 5 - TRABALHO E EMPREGO & 16 - DEFESA \\
\hline \multirow[t]{2}{*}{6 - EDUCAÇÃO E CULTURA } & 17 - CIÊNCIA, TECNOLOGIAE \\
\hline & COMUNICAÇÕES \\
\hline 7 - AMBIENTE & 18 - COMÉRCIO EXTERNO \\
\hline 8 - ENERGIA & $19-$ POLÍTICA EXTERNA \\
\hline \multirow[t]{3}{*}{10 - TRANSPORTE } & 20 - GOVERNO E ADMINISTRAÇÃO \\
\hline & PÚBLICA \\
\hline & 21 - RECURSOS NATURAIS \\
\hline
\end{tabular}

Fonte: Bevan (2014).

O processo de codificação foi realizado manualmente. Para garantir a validade do procedimento, os documentos foram codificados duas vezes, por indivíduos diferentes. Em alguns casos, nos quais os dois codificadores divergiram em relação à categorização, o grupo de pesquisa analisou cada situação, definindo a classificação mais apropriada.
Uma questão metodológica relevante apresentada pelo corpus documental aqui analisado refere-se à necessidade de padronização dos documentos analisados, sobretudo no que diz respeito à variação na extensão desses documentos. Em uma análise comparativa, em que se utiliza a frequência no aparecimento de indicadores ao longo do 
Felipe Gonçalves Brasil - Ana Claudia Niedhardt Capella

tempo, o uso dos dados brutos pode enviesar ou mesmo invalidar a análise. Uma forma de balancear essas distorções tornando a análise longitudinal possível é o tratamento percentual dos dados, no qual consideramos cada documento anual como universo da análise, representando $100 \%$ dos dados. A partir dessa concepção, cada política codificada representará um percentual da atenção sobre aquele documento.

\section{CAPACIDADE, DIVERSIDADE E ELASTI- CIDADE DA AGENDA}

A capacidade da agenda é um dos principais fatores que afetam a atuação concreta dos governos em transformar suas preferências em resultados, em políticas públicas de fato. Como a abordagem de definição de agenda ilustra, há um desequilíbrio permanente entre a grande variedade de questões que precisam de atenção e o tamanho finito da agenda, o que significa que a maioria das questões, na maior parte das vezes, recebe pouca ou nenhuma atenção. Em um contexto de recessão econômica, por exemplo, caracterizado por aumento do deficit públi$\mathrm{co}$, deficit fiscal e desemprego, há pouco espaço na agenda do governo para outras questões, apesar da urgência em tantos outros campos como a educação, a saúde ou o meio ambiente. A questão mais importante, nesse determinado momento, é superar a recessão econômica, e isso faz com que outras reformas políticas importantes, como a expansão do estado de bem-estar social ou lidar com as crescentes desigualdades sociais e aumento da violência urbana, assumam um segundo plano comparado a esses problemas mais urgentes (Chaques, Palau, \& Baumgartner, 2015; Jones \& Baumgartner, 2005).
Já o conceito de diversidade da agenda não se atenta à quantidade de temas inseridos na agenda, mas descreve como a atenção é distribuída entre as questões possíveis, fornecendo uma medida mensurável sobre a variação da atenção que forma a agenda. Quando analisamos a capacidade e a diversidade da agenda, a escassez de espaço nas prioridades de políticas significa que os governos, às vezes, não conseguem implementar nem mesmo suas principais prioridades. Isso porque eles estão lidando com ambientes de grande fricção política, institucional e cognitiva sobre a interpretação de problemas e soluções. Exemplos desses ambientes pedem construções de bases políticas, tempo e recursos lidando com custos de informação e de decisão.

No entanto, ao longo do tempo, a lista de problemas urgentes muda, e a agenda se abre para algumas reformas de políticas que não poderiam ter sido feitas em outros períodos. Assuntos novos surgem, mais espaço é aberto para novos temas e novas políticas. Atores entram em cena e inserem suas demandas, seus problemas e alternativas. Não que esses temas não fossem importantes antes, ou que esses atores não existissem, mas simplesmente porque outras crises eram mais urgentes, e não havia espaço para mais assuntos e atores na agenda. Alguns fatores, como a estabilidade econômica doméstica e internacional ou os altos custos de transação em momentos de transição, são suficientes para aumentar ou reduzir a capacidade de agenda e a diversidade das políticas ali inseridas num determinado tempo (Baumgarther \& Jones, 2002; Jones \& Baumgartner, 2012; Chaques, Palau, \& Baumgartner, 2015; Green-Perdersen, 2007). 
Isso implica dizer que a capacidade e a diversidade da agenda são reduzidas quando há fortes crises, assuntos de muita importância e baixa coesão política sobre alternativas e soluções. Ao mesmo tempo que a capacidade e a diversidade aumentam quando a democracia se consolida, as bases da governabilidade tornam-se mais sólidas, e as crises dão espaço para um ambiente mais ameno e passível de mudanças e de abertura para novos atores e demandas. É nesse momento, em que novos atores entram em cena, que mais promissoras e plurais (diversas) são as relações e possibilidades de atuação dos governos.

\section{ANÁLISE DAS MENSAGENS AO CON- GRESSO (DE 2003 A 2014): PRINCIPAIS RESULTADOS}

Após o tratamento dos dados mapeados nas Mensagens ao Congresso Nacional e conversão para valores percentuais, alguns tipos de análises foram realizados. O primeiro é caracterizado pela capacidade da agenda na qual mapeamos a quantidade de temas que aparecem em cada documento, como também apresentamos a análise de frequência do aparecimento de cada tema (código) ao longo do tempo. Nesse tipo de estudo, evidenciamos manutenções e alterações na atenção manifestada nos documentos analisados em relação a cada um dos códigos que representam políticas setoriais distintas. A segunda análise é realizada por meio de estudos de diversidade e elasticidade, em que utilizamos a ferramenta de entropia $\mathrm{H}$ de Shannon para mensurar o nível de diversidade de assuntos que cada documento apresenta. A medida da entropia $\mathrm{H}$ de Shannon é adaptada da teoria da informação para estimar a diversidade da atenção na agenda (Jones \& Baumgartner, 2005). A H de Shannon é uma medida probabilística sobre a disseminação de atenção que mede a distribuição de atenção entre os códigos estudados, ou seja, a concentração relativa ou dispersão dos dados. Neste trabalho, utilizamos o Indicador da Entropia $\mathrm{H}$ de Shannon baseado no logaritmo natural (número de Euler: e)

$$
H(X)=-\sum_{i=1}^{n} p\left(x_{i}\right) \times \ln \left(p\left(x_{i}\right)\right),
$$

em que $x_{i}$ representa a dimensão (cada código ou subcódiogo), $p\left(x_{i}\right)$ refere-se à proporção de atenção recebida por $x_{i}, \ln \left(p\left(x_{i}\right)\right)$ é o logaritmo natural da proporção de atenção recebida, e n é o total de códigos ou subcódigos em análise. 
Felipe Gonçalves Brasil - Ana Claudia Niedhardt Capella

Quadro 2. Distribuição de atenção sobre códigos ao longo dos anos e por governos

\begin{tabular}{|c|c|c|c|c|c|c|c|c|c|c|c|c|}
\hline & \multicolumn{4}{|c|}{ LULA 1} & \multicolumn{4}{|c|}{ LULA 2} & \multicolumn{4}{|c|}{ DILMA 1} \\
\hline & 2003 & 2004 & 2005 & 2006 & 2007 & 2008 & 2009 & 2010 & 2011 & 2012 & 2013 & 2014 \\
\hline 1_Macroeconomia & $13 \%$ & $15 \%$ & $13 \%$ & $11 \%$ & $33 \%$ & $13 \%$ & $31 \%$ & $35 \%$ & $11 \%$ & $18 \%$ & $12 \%$ & $8 \%$ \\
\hline $\begin{array}{l}\text { 2_Direitos Civis, Direitos das Minorias } \\
\text { e Liberdade }\end{array}$ & $9 \%$ & $0 \%$ & $0 \%$ & $0 \%$ & $0 \%$ & $1 \%$ & $1 \%$ & $0 \%$ & $2 \%$ & $0 \%$ & $0 \%$ & $5 \%$ \\
\hline 3_Saúde & $0 \%$ & $0 \%$ & $0 \%$ & $0 \%$ & $0 \%$ & $3 \%$ & $0 \%$ & $0 \%$ & $8 \%$ & $8 \%$ & $6 \%$ & $2 \%$ \\
\hline 4_Agricultura, pecuária e pescas & $0 \%$ & $0 \%$ & $9 \%$ & $6 \%$ & $0 \%$ & $1 \%$ & $3 \%$ & $0 \%$ & $1 \%$ & $2 \%$ & $4 \%$ & $5 \%$ \\
\hline 5_Trabalho e emprego & $0 \%$ & $9 \%$ & $4 \%$ & $4 \%$ & $4 \%$ & $3 \%$ & $1 \%$ & $1 \%$ & $3 \%$ & $6 \%$ & $2 \%$ & $2 \%$ \\
\hline 6_Educação e cultura & $0 \%$ & $3 \%$ & $4 \%$ & $11 \%$ & $5 \%$ & $12 \%$ & $0 \%$ & $6 \%$ & $12 \%$ & $9 \%$ & $8 \%$ & $10 \%$ \\
\hline 7_Ambiente & $0 \%$ & $0 \%$ & $0 \%$ & $0 \%$ & $1 \%$ & $0 \%$ & $0 \%$ & $1 \%$ & $6 \%$ & $1 \%$ & $2 \%$ & $1 \%$ \\
\hline 8_Energia & $0 \%$ & $0 \%$ & $1 \%$ & $7 \%$ & $4 \%$ & $5 \%$ & $1 \%$ & $3 \%$ & $6 \%$ & $0 \%$ & $6 \%$ & $4 \%$ \\
\hline 10_Transportes & $0 \%$ & $0 \%$ & $0 \%$ & $3 \%$ & $6 \%$ & $4 \%$ & $3 \%$ & $1 \%$ & $3 \%$ & $5 \%$ & $10 \%$ & $7 \%$ \\
\hline 12_Justiça e Administração Pública & $4 \%$ & $6 \%$ & $3 \%$ & $0 \%$ & $1 \%$ & $5 \%$ & $1 \%$ & $3 \%$ & $8 \%$ & $7 \%$ & $5 \%$ & $6 \%$ \\
\hline 13_Políticas Sociais & $9 \%$ & $18 \%$ & $13 \%$ & $18 \%$ & $20 \%$ & $11 \%$ & $19 \%$ & $13 \%$ & $13 \%$ & $10 \%$ & $8 \%$ & $6 \%$ \\
\hline 14_Desenvolvimento Local e Habitação & $0 \%$ & $0 \%$ & $3 \%$ & $11 \%$ & $4 \%$ & $2 \%$ & $0 \%$ & $4 \%$ & $4 \%$ & $4 \%$ & $2 \%$ & $1 \%$ \\
\hline $\begin{array}{l}\text { 15_Setor Financeiro, Indústria e } \\
\text { Comércio }\end{array}$ & $0 \%$ & $0 \%$ & $9 \%$ & $8 \%$ & $1 \%$ & $0 \%$ & $13 \%$ & $6 \%$ & $2 \%$ & $4 \%$ & $4 \%$ & $3 \%$ \\
\hline 16_Defesa & $0 \%$ & $0 \%$ & $0 \%$ & $0 \%$ & $0 \%$ & $0 \%$ & $0 \%$ & $3 \%$ & $1 \%$ & $4 \%$ & $2 \%$ & $1 \%$ \\
\hline 17_Ciência, Tecnologia e Comunicações & $0 \%$ & $0 \%$ & $1 \%$ & $0 \%$ & $0 \%$ & $1 \%$ & $0 \%$ & $0 \%$ & $1 \%$ & $1 \%$ & $4 \%$ & $3 \%$ \\
\hline 18_Comércio Externo & $0 \%$ & $3 \%$ & $6 \%$ & $4 \%$ & $6 \%$ & $4 \%$ & $6 \%$ & $3 \%$ & $1 \%$ & $2 \%$ & $1 \%$ & $3 \%$ \\
\hline 19_Política Externa & $9 \%$ & $6 \%$ & $20 \%$ & $6 \%$ & $5 \%$ & $20 \%$ & $13 \%$ & $10 \%$ & $5 \%$ & $8 \%$ & $9 \%$ & $16 \%$ \\
\hline 20_Governo e Administração Pública & $57 \%$ & $40 \%$ & $14 \%$ & $10 \%$ & $10 \%$ & $12 \%$ & $8 \%$ & $9 \%$ & $16 \%$ & $9 \%$ & $10 \%$ & $15 \%$ \\
\hline 21_Recursos Naturais & $0 \%$ & $0 \%$ & $0 \%$ & $0 \%$ & $1 \%$ & $2 \%$ & $0 \%$ & $1 \%$ & $0 \%$ & $1 \%$ & $3 \%$ & $2 \%$ \\
\hline Número de dados brutos/Capacidade & 23 & 33 & 70 & 72 & 82 & 94 & 72 & 69 & 192 & 218 & 410 & 351 \\
\hline Número de páginas da Introdução & 3 & 2 & 8 & 2 & 2 & 2 & 3 & 3 & 5 & 6 & 15 & 10 \\
\hline Tópicos representando $50 \%$ do total & 1 & 2 & 4 & 4 & 2 & 4 & 2 & 3 & 4 & 5 & 6 & 5 \\
\hline Diversidade & 1,36 & 1,72 & 2,29 & 2,35 & 2,12 & 2,40 & 1,97 & 2,15 & 2,62 & 2,61 & 2,72 & 2,65 \\
\hline
\end{tabular}

Nota: Os dados cobrem a Introdução das Mensagens ao Congresso Nacional de 2003 a 2014. As porcentagens somam $100 \%$ nas colunas, indicando a parcela relativa de atenção em todos os subtópicos. As últimas linhas mostram, respectivamente, a capacidade, o número de páginas de cada documento anual, o número de tópicos que compõem metade do total e a diversidade calculada por meio da entropia de $\mathrm{H}$ de Shannon. Além disso, considerando que o número de variáveis é 19, a diversidade máxima possível é $\ln (19)=2,95$ 
Em uma análise de perspectiva longitudinal em que se considera a distribuição de atenção dos indicadores ao longo dos anos, o cenário apresentado pelo Quadro 2 permite algumas considerações: a primeira delas está relacionada à concentração de tópicos que somam $50 \%$ dos valores totais e à diversidade da atenção anual. Com relação à primeira análise de concentração, é importante verificar como os índices mudam e a capacidade e diversidade aumentam ao longo dos anos. No primeiro ano do governo Lula, em 2003, um único indicador (governo e administração pública) equivale a $57 \%$ de toda a parte inicial que compõe a Mensagem ao Congresso daquele ano (e que foi lida por Lula na abertura da sessão legislativa), mostrando um alto valor de concentração da atenção da presidência sobre assuntos relacionados ao pacto federativo, à relação entre os poderes, à administração pública e à função do governo.

Os resultados do primeiro ano do primeiro governo Lula dialogam fortemente com a teoria de formação de agenda, na medida em que o período evidencia uma grande mudança no cenário político partidário brasileiro, com a primeira vitória do Partido dos Trabalhadores para a chefia do Executivo federal. O período, marcado por grande apreensão e temor de alguns setores da sociedade, tanto no ambiente doméstico quanto nas relações exteriores, é caracterizado por uma agenda diminuta, com baixa capacidade, alta concentração e extremamente direcionada. Como evidenciam os dados, as prioridades estão relacionadas com a construção de uma base política dentro do ambiente institucional, com o diálogo sobre relações interinstitucionais, sobre a relação dos Poderes Executivo e Legislativo, eviden- ciados pelo aparecimento massivo de temas vinculados ao próprio governo e administração interna de maneira ampla, sem muitas especificações setoriais ou proposições temáticas. Tais achados são explicados pelos altos custos de decisões, de informações e de transações característicos de momentos de rupturas e de grandes mudanças, como a ocorrida na eleição de Lula em 2003.

Com o passar dos anos, ainda no primeiro governo Lula, esse indicador vai se tornando cada vez menos concentrado, mostrando maior estabilidade nos ambientes interno e externo, crescimento de condições econômicas e políticas para abertura da agenda, como redução das friç̧ões institucionais e cognitivas, menores custos de decisão e de informação, e, também, atuação do governo na proposição de novos temas prioritários. Em 2004, são dois os indicadores que somam mais de $50 \%$ da atenção no documento analisado. $\mathrm{O}$ mesmo indicador, governo e administração pública, representa $40 \%$ da ação sobre as mensagens daquele ano e, somado à atenção sobre macroeconomia (15\%), configura uma leve redução da concentração. Nos anos de 2005 e 2006, a concentração é ainda mais diluída, e novos indicadores aparecem nas prioridades do governo, que agora totalizam quatro entre os que, somados, configuram $50 \%$ da atenção do período. Em 2005, a política externa e as políticas sociais ascendem entre os indicadores com maiores níveis de atenção. Em 2006, são destacadas as políticas de educação e políticas de desenvolvimento local e habitação.

A evolução do primeiro governo Lula é um grande exemplo de ampliação da capacidade de agenda, com ampliação de diversida- 
Felipe Gonçalves Brasil - Ana Claudia Niedhardt Capella

de temática. A capacidade sobe de 23 para 72 dados, de 2003 para 2006, o número de temas que concentram $50 \%$ da atenção do presidente sobe de um, em 2003, para quatro, em 2006, e o índice de diversidade, cuja escala vai de 0 a 2,95, sobe de 1,36 para 2,35 nesse período. As crises institucionais e os momentos de concentração de atenção vão dando lugar, com o passar do tempo, a uma agenda mais plural e diversa, com novas propostas setoriais e novos atores de grande importância nas prioridades do presidente da República, demonstrando, assim, um período de alta elasticidade da agenda governamental.

Já no primeiro ano do segundo governo Lula, 2007, há novo aumento da concentração, com crescimento da atenção sobre questões macroeconômicas e sobre políticas sociais. Nesse ano, esses dois indicadores, juntos, somam mais de $50 \%$ da atenção nas Mensagens ao Congresso do ano. O mesmo padrão é encontrado no ano de 2009, mas por motivos diferentes. $O$ ano de 2008 apresenta um padrão de atenção bem diferente dos demais anos do segundo governo Lula. $O$ indicador de maior atenção passa a ser de política externa e, ainda que o tema da macroeconomia continue entre as prioridades, o percentual de atenção nesse ano cai de maneira nítida. Outros dois temas compõem $50 \%$ da atenção em 2008: políticas de educação e governo e administração pública. Em 2010, o crescimento da atenção sobre políticas macroeconômicas aumenta, consequentemente, a concentração da atenção nas Mensagens ao Congresso Nacional. Políticas sociais e política externa somam-se aos três indicadores que refletem metade da atenção do documento. Tais achados estão diretamente relacionados com a força da agenda externa, sobretudo da crise econômica internacional que acometeu as grandes economias entre os anos de 2007 e 2010, na agenda nacional. A maior participação do Brasil no cenário externo, fruto do bom desempenho econômico do País, trouxe para a agenda doméstica prioridades que não existiam em outros anos, como demonstrado nas prioridades de 2008 e 2009, em que política externa e economia concentram $50 \%$ da atenção presidencial.

Com o governo Dilma, em 2011, nota-se uma redução da concentração, ao mesmo tempo que o tamanho dos dados analisados aumenta de forma significativa. Se, nos governos Lula, dois ou três dados somavam $50 \%$ da atenção dos documentos analisados, no governo Dilma, esse indicador só é alcançado com a soma de cinco ou seis políticas setoriais diferentes. Além da manutenção dos indicadores de macroeconomia, políticas sociais, governo e administração pública e educação, também aparecem na agenda outras políticas de destaque: em 2012, as políticas de saúde e políticas de justiça e administração interna; em 2013, há um pico de atenção sobre as políticas de transporte, que aparecem como o segundo elemento concentrador de atenção no período. O mesmo padrão é encontrado no ano seguinte, 2014.

Os dados obtidos sobre a capacidade e prioridades do governo Dilma abrem novos caminhos para a análise sobre agenda governamental no período estudado. Três pontos são importantes e merecem a atenção: o primeiro deles está relacionado ao alargamento da capadidade de agenda, no qual diversos temas antes não mencionados surgem no texto introdutório do governo Dilma, como é o caso das políticas de saúde, de defesa e 
de transporte. O segundo ponto mostra um acompanhamento no aumento da diversidade, ou seja, além de maior, a agenda também é mais ampla e menos concentrada. Por fim, o terceiro ponto mostra, também, a inversão dos temas prioritários quando comparados aos do governo Lula 1 e 2 . Tais elementos podem nos levar a diversos cenários que explicam tais mudanças. Alguns deles, mais pontuais, são explicados por eventos focalizados (focusing events), como a ascensão de questões sobre políticas de transportes e a aproximação de grandes eventos esportivos, como a Copa do Mundo e os Jogos Olímpicos, ou mesmo com as Jornadas de Junho de 2013. Já outras políticas ascendem por atuação direta do próprio governo, como as políticas de saúde a partir de 2011, sem necessidade de um fator causal externo.
A última linha do Quadro 2 apresenta os dados de diversidade de cada ano, calculados a partir da diversidade máxima $=2,95$. Com exceção ao ano de 2009, onde há uma queda na diversidade, é possível verificar um processo quase contínuo de crescimento da diversidade de temas que captaram a atenção da presidência da República na porção inicial das Mensagens ao Congresso Nacional. No ano de 2003, primeiro ano do governo Lula, a baixa diversidade é retratada pelo indicador de entropia igual a 1,365. Na outra ponta, os dois últimos governos Dilma registram os maiores índices de diversidade, com valores próximos de 2,73 e 2,65, muito próximos da diversidade máxima de 2,95. Nos estudos sobre agenda, a diversidade tem papel de extrema importância para compreensão das prioridades dos policymakers. $\mathrm{O}$ gráfico abaixo representa essa diferença na diversidade da atenção ao longo do tempo.

Gráfico 1. Distribuição de atenção sobre códigos ao longo dos anos de 2003 a 2014

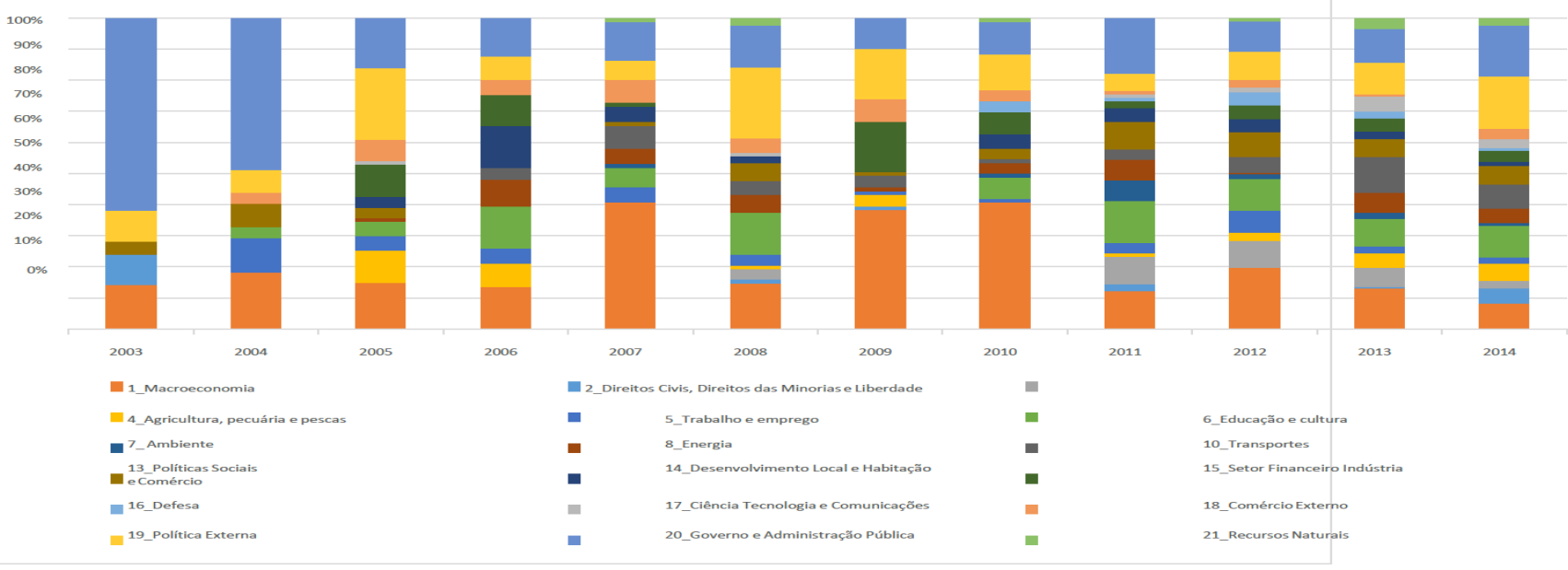

Nota: Os dados cobrem a Introdução das Mensagens ao Congresso Nacional de 2003 a 2014. As porcentagens somam $100 \%$ nas colunas, indicando a parcela relativa de atenção em todos os subtópicos. 
O Gráfico 1 é uma ilustração sobre a dinâmica da atenção sobre diversas políticas que captaram a atenção da presidência da República nas Mensagens ao Congresso Nacional. Nessa representação, cada um dos 19 indicadores compõe uma fração da atenção, e, juntos, somam $100 \%$ do documento anual analisado. Quanto maior for a atenção sobre um indicador, maior será o seu tamanho representado na barra, assim como quanto mais cores e mais divisões existirem em uma barra, maior é a quantidade de indicadores presentes naquele documento analisado. Somado aos indicadores de concentração e de diversidade, esse gráfico permite a análise do comportamento longitudinal da atenção sobre cada indicador ao longo do tempo. Por meio dessa análise, é possível aferir quais indicadores detêm a concentração constante dos presidentes e quais entram e saem de sua lista de prioridades.

Retomando brevemente a tese geral da pontuação, selecionamos políticas setoriais dos governos estudados para ilustrar três tipos de comportamentos da atenção governamental sobre políticas públicas. O primeiro exemplo é representado pela própria pontuação do equilíbrio, ou seja, políticas que, por diferentes razões, se mantêm estáveis na atenção presidencial por longos períodos, mas que, em determinado momento, sofrem um pico de atenção (Gráfico 2). O segundo comportamento ilustra o incrementalismo, ou seja, políticas que recebem a atenção dos governos, mas de modo estável e com pequenas e incrementais mudanças ao longo do tempo (Gráfico 3). O terceiro e último padrão de comportamento está relacionado com as políticas que não entram na agenda ou ocupam um lugar insignificante nas prioridades analisadas (Gráfico 4).

As políticas que configuram os indicadores de macroeconomia, política externa e educação formam um conjunto que registra os maiores níveis de atenção e maior grau de permanência ao longo do período analisado. Não se pode dizer, no entanto, que a atenção sobre essas políticas é equilibrada e constante ao longo do tempo. Por exemplo: a média de atenção sobre esse o indicador de macroeconomia é de $18 \%$, mas nota-se a existência de picos de atenção sobre esse tópico entre 2007 e 2010 que chegam a 33\%. Sobre política externa, a média de $16 \%$ é caracterizada por picos de $20 \%$ e momentos de baixa atenção de até $9 \%$.

Gráfico 2. Atenção sobre o indicador de macroeconomia, política externa e educação ao longo do tempo

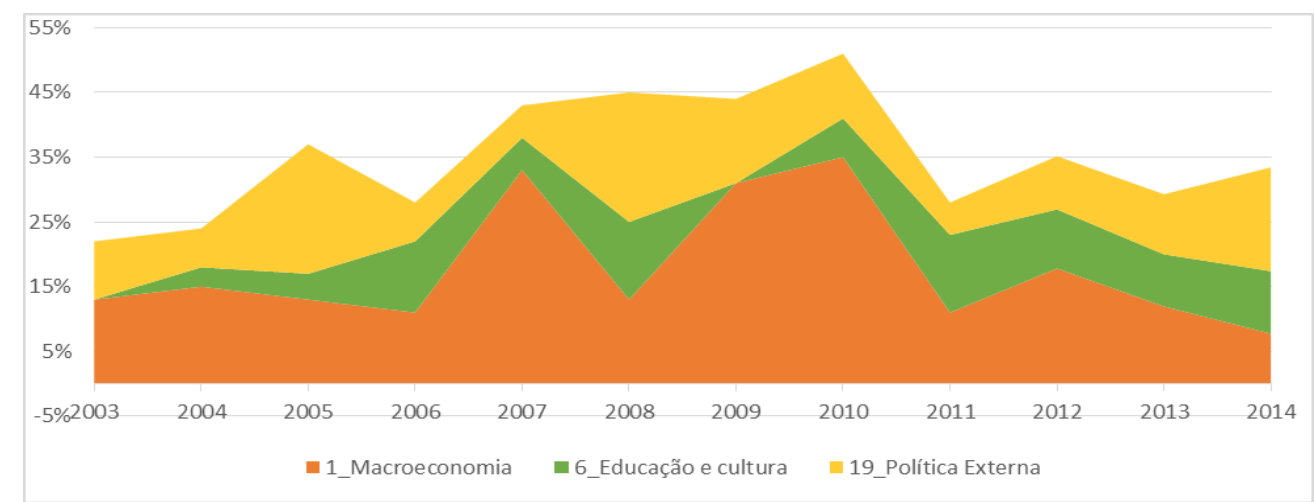


A dispersão gráfica da imagem anterior evidencia, tanto para as políticas macroeconômicas quanto para as políticas de educação e política externa, um comportamento com três fases: a primeira, que engloba o primeiro governo Lula, de 2003 a 2006, é marcada por um período de atenção existente, equilibrada e estável sobre esses temas. É possível verificar, sobre esses três indicadores, moderados e constantes níveis de atenção ao longo dos primeiros quatro anos analisados. O segundo momento, que ocorre nos anos de 2007, 2010 e 2012, demonstra ruptura no equilíbrio da atenção sobre esses indicadores, mudando o perfil caracterizado no primeiro momento. A pontuação no equilíbrio é demonstrada por picos de atenção que chegam a alcançar duas vezes o seu valor médio. $O$ terceiro momento, por fim, é caracterizado pelo retorno do equilíbrio e manutenção de valores médios de atenção, configurando um cenário próximo daquele encontrado na primeira fase, anterior à pontuação. Baumgartner e Jones $(1993,2005)$ descrevem esse comportamento como típico de processos de mudanças em políticas. Nos casos selecionados, a mudança na atenção governamental pode ser explicada por diversos fatores que precisariam ser estudados caso a caso. No entanto, a literatura mostra que mudanças na atenção podem ser causadas por fatores como mudança de pessoal, alteração de cargos, entrada e saída de novos atores, eventos focalizados, mudanças no ambiente internacional, crises econômicas, apararecimento de novas tecnologias.

Outro tipo de comportamento é caracterizado pelo incrementalismo. De acordo com Baumgartner e Jones (1993, 2005), esses momentos são marcados por pequenos ajustes e mudanças graduais nas políticas. A disposição gráfica de momentos incrementais evidencia continuidades e equilíbrio na atenção sobre um indicador. Um exemplo claro dessa situação pode ser demonstrado na análise das políticas setoriais ao longo do período analisado. Apesar de pequenas movimentações, para cima ou para baixo, não há grandes pontuações na atenção sobre essa política nem decréscimos que possam significar bloqueio na entrada desse tema na agenda da presidência.

Gráfico 3. Atenção sobre o indicador de Políticas Sociais ao longo do tempo

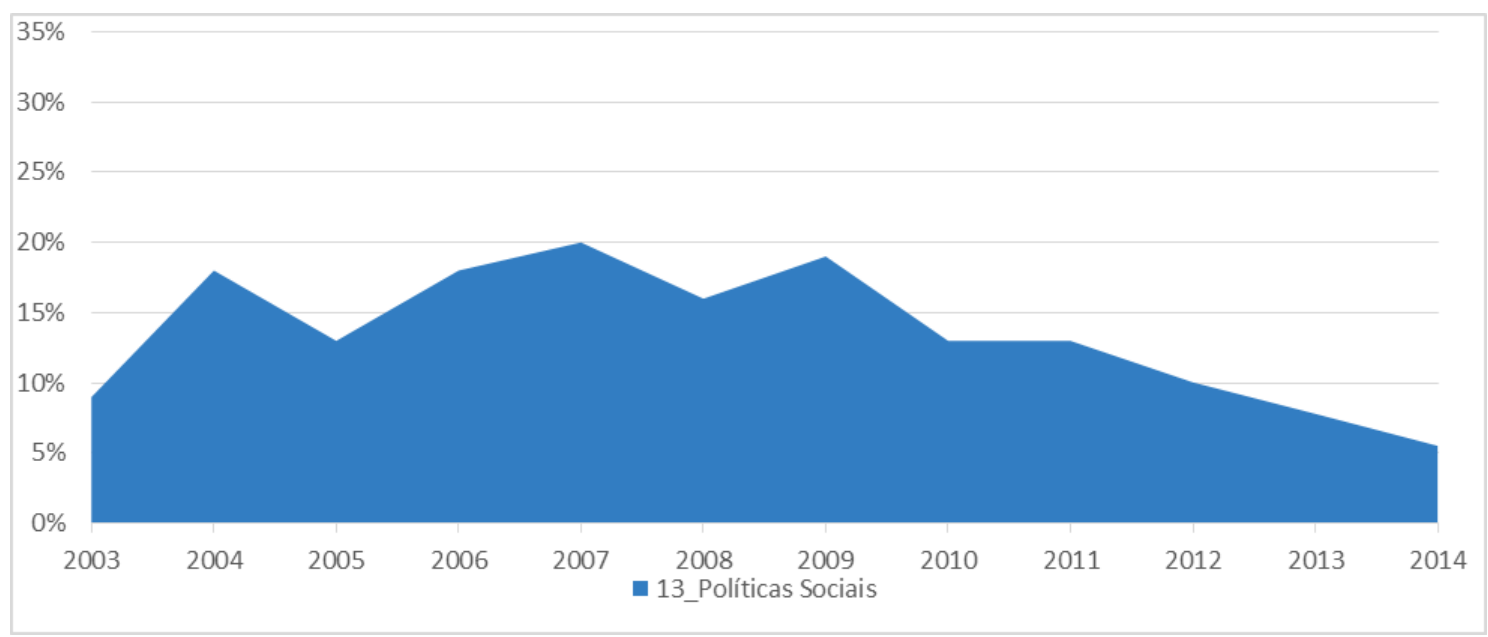


Por fim, outro padrão encontrado sobre a atenção aos indicadores pode ser notado nas políticas de recursos naturais, defesa e direitos civis, das minorias e liberdade. Nesses casos, há baixa atenção dos policymakers, ocorrendo, inclusive, momentos de bloqueio ou de não aparecimento desses assuntos nas prioridades explicitadas na introdução das Mensagens ao Congresso. $O$ gráfico abaixo ilustra o caso desses três indicadores

Gráfico 4. Atenção sobre os indicadores de recursos naturais, defesa e direitos civis, das minorias e liberdade ao longo do tempo

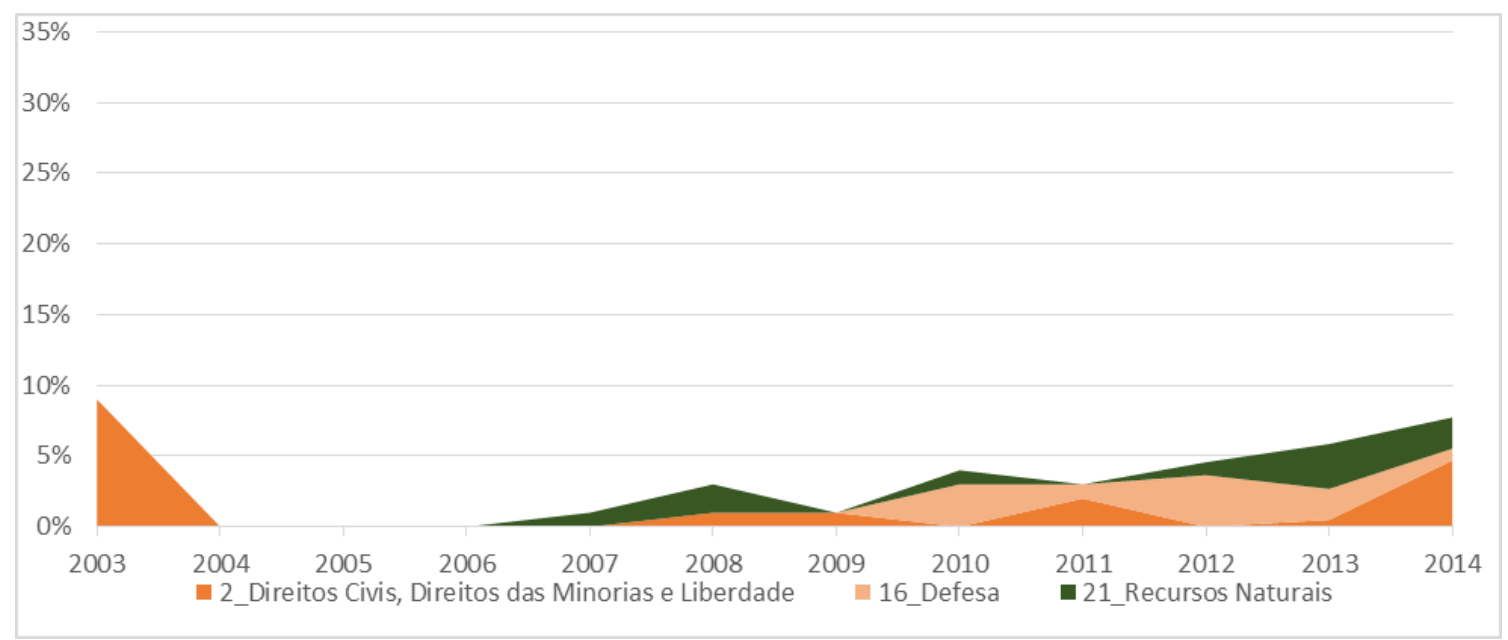

Outra forma de analisar os dados é por meio dos governos, e não pelos anos. O Quadro 3 abaixo sistematiza os dados de acordo com os três governos inseridos no escopo temporal dessa pesquisa: Lula 1 (2003-2006); Lula 2 (2007-2010); Dilma (2011-2014). 
Quadro 3. Distribuição de atenção sobre códigos por Governo

\begin{tabular}{|c|c|c|c|c|}
\hline & LULA 1 & LULA 2 & DILMA & Média \\
\hline 1_Macroeconomia & $13 \%$ & $28 \%$ & $12 \%$ & $18 \%$ \\
\hline 2_Direitos Civis, Direitos das Minorias e Liberdade & $2 \%$ & $1 \%$ & $2 \%$ & $2 \%$ \\
\hline 3_Saúde & $0 \%$ & $1 \%$ & $6 \%$ & $2 \%$ \\
\hline 4_Agricultura, pecuária e pescas & $4 \%$ & $1 \%$ & $3 \%$ & $3 \%$ \\
\hline 5_Trabalho e emprego & $4 \%$ & $2 \%$ & $3 \%$ & $3 \%$ \\
\hline 6_Educação e cultura & $5 \%$ & $6 \%$ & $10 \%$ & $7 \%$ \\
\hline 7_Ambiente & $0 \%$ & $1 \%$ & $3 \%$ & $1 \%$ \\
\hline 8_Energia & $2 \%$ & $3 \%$ & $4 \%$ & $3 \%$ \\
\hline 10_Transportes & $1 \%$ & $4 \%$ & $6 \%$ & $4 \%$ \\
\hline 12_Justiça e Administração Pública & $3 \%$ & $3 \%$ & $7 \%$ & $4 \%$ \\
\hline 13_Políticas Sociais & $15 \%$ & $16 \%$ & $9 \%$ & $13 \%$ \\
\hline 14_Desenvolvimento Local e Habitação & $4 \%$ & $3 \%$ & $3 \%$ & $3 \%$ \\
\hline 15_Setor Financeiro, Indústria e Comércio & $4 \%$ & $5 \%$ & $3 \%$ & $4 \%$ \\
\hline 16_Defesa & $0 \%$ & $1 \%$ & $2 \%$ & $1 \%$ \\
\hline 17_Ciência Tecnologia e Comunicações & $0 \%$ & $0 \%$ & $2 \%$ & $1 \%$ \\
\hline 18_Comércio Externo & $3 \%$ & $5 \%$ & $2 \%$ & $3 \%$ \\
\hline 19_Política Externa & $10 \%$ & $12 \%$ & $10 \%$ & $11 \%$ \\
\hline 20_Governo e Administração Pública & $30 \%$ & $10 \%$ & $13 \%$ & $18 \%$ \\
\hline 21_Recursos Naturais & $0 \%$ & $1 \%$ & $2 \%$ & $1 \%$ \\
\hline
\end{tabular}

Nesse cenário, é possível verificar as políticas que tiveram maior e menor atenção na introdução das Mensagens ao Congresso Nacional de acordo com os governos. Iniciando a análise pelas políticas de menor atenção, alguns comportamentos merecem destaque. Ao longo dos três governos analisados, a atenção sobre políticas sobre direitos civis, direitos das minorias e liberdade, políticas sobre recursos naturais, ciência tecnologia e comunicações, e políticas de meio ambiente são as que concentram menor atenção dos presidentes nas Mensagens ao Congresso. Em especial sobre o governo Lula, chama atenção a baixa prioridade atribuída às políticas de saúde, setor historicamente relevante para o Brasil e que passa a concentrar maior atenção nos dois primeiros anos do governo Dilma.
Para mapear as políticas de maior atenção, adotamos como limite o índice de 5\% sobre o total de cada governo, ou seja, indicadores que tenham mais de $5 \%$ de atenção em cada governo são considerados entre os de maior destaque. No primeiro mandato de Lula, é possível verificar a atenção concentrada em quatro políticas distintas: governo e administração pública; políticas sociais; macroeconomia e política externa. Ainda que com maior diluição dos percentuais de atenção, o segundo governo de Lula mostra altos índices de continuidade sobre a atenção das mesmas políticas priorizadas no governo anterior. Há, no entanto, uma inversão sobre os percentuais e ordem de atenção sobre essas políticas: macroeconomia passa a ser o indicador de maior atenção, seguido por políticas sociais, política externa e governo e administração pública, indi- 
cador de maior atenção no primeiro governo. Também há o crescimento e inclusão de um novo tema, que passa a capturar $6 \%$ da atenção da presidência no documento analisado: as políticas de educação e as grandes reformas no ensino superior brasileiro promovidas na administração do ministro Fernando Haddad. Por fim, o governo Dilma apresenta um cenário ainda mais diversifi- cado, em que a atenção é dividida de maneira menos concentrada, o que inclui entre os temas prioritários, além dos já citados nos governos anteriores, as políticas de saúde, justiça e administração interna e políticas de transportes. O Gráfico 5, a seguir, apresenta o comportamento desses indicadores ao longo dos três governos.

Gráfico 5. Variação na atenção em políticas setoriais por governo (2003-2014)

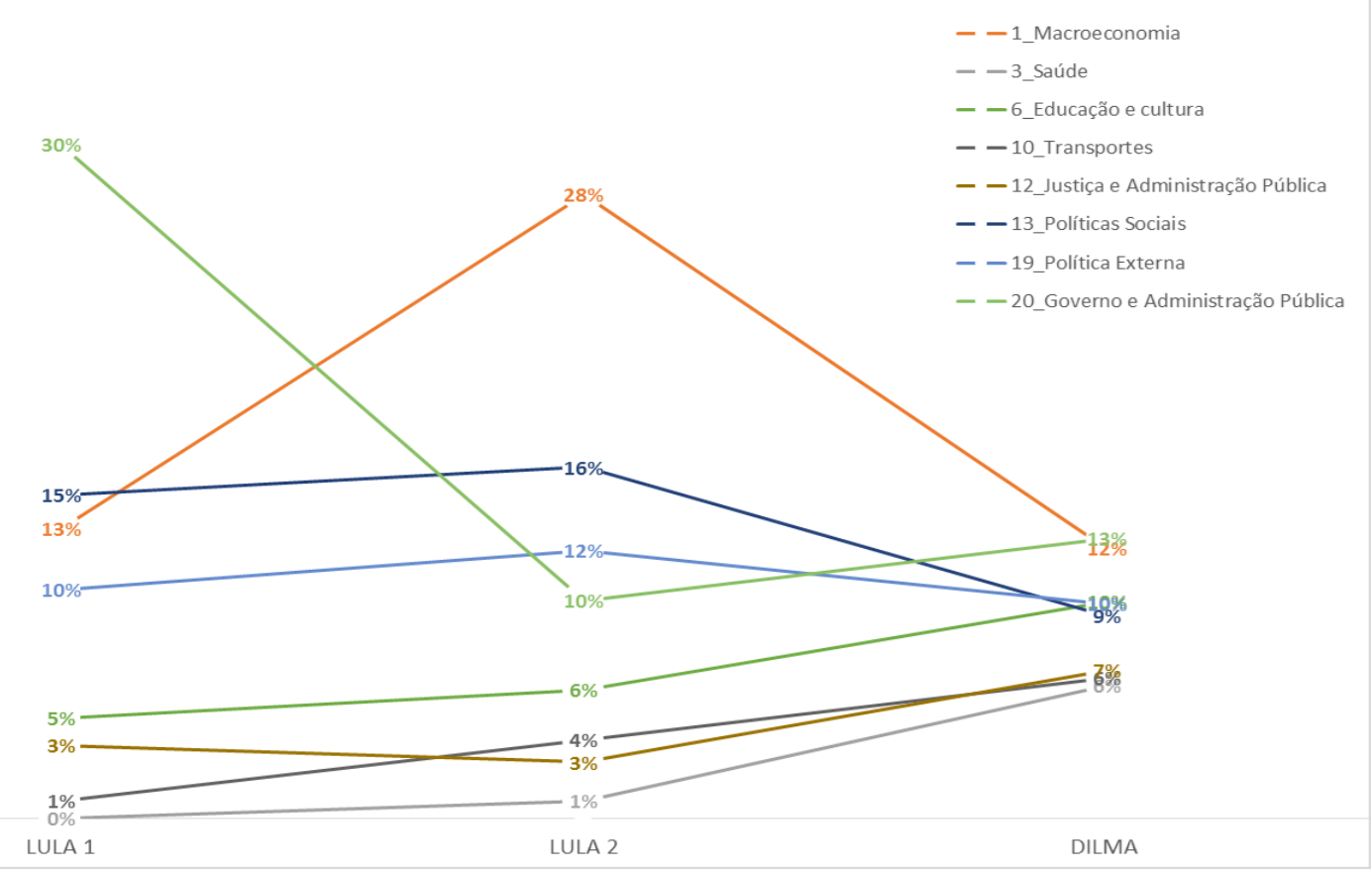

\section{CONSIDERAÇÕES FINAIS}

Considerando a multiplicidade de problemas existentes e a capacidade limitada de atenção disponível para cada um deles, o processo de definição da agenda está relacionado à forma como a atenção é alocada (Jones \& Baumgartner, 2005). As teorias sobre agenda mostram que, na ausência de atenção sobre um tema, não há expectativa de mudança em políticas públicas (Baum- gartner \& Jones, 2015). Além disso, os grandes teóricos sobre formação da agenda e mudança em políticas públicas apontam para a existência de alguns gatilhos com maior potencial de promover tais mudanças. Entre eles, estão o turnover, quando há trocas importantes em cargos do Legislativo e no Executivo, novos períodos eleitorais com trocas de representantes; os eventos focalizados, como grandes desastres naturais, situações de crises pontuais e de grande mobilização 
pública; e o national mood, descrito como o momento em que há estabilidade política, econômica e um bom clima institucional para a realização de mudanças.

Os dados analisados neste trabalho dialogam fortemente com essas teorias, e também com os fatores que podem causar mudanças na prioridade dos presidentes e, consequentemente, na agenda governamental. Baseado nisso, três conclusões podem ser apontadas pela análise aqui realizada: a primeira delas está vinculada aos períodos de maior fricção cognitiva e institucional, carcaterizada, sobretudo, por momentos de mudanças macrossistêmicas em que há alterações significativas da lógica vigente. Exemplo dessas mudanças ou possibilidade de mudanças são os períodos eleitorais e a própria eleição de Lula em 2003. Há, nesse período, uma grande ruptura no cenário político partidário na chefia do Executivo nacional brasileiro, sobretudo na concepção ideológica. Esse turnover age diretamente no national mood, e a apreensão dos mais variados setores da sociedade, sobretudo as elites econômicas, cria barreiras e demanda adpatações na agenda governamental do primeiro governo Lula (20032006). É esse sentimento nacional de desconfiança e insegurança que faz com que a capacidade e a diversidade da agenda se tornem diminutas, fechadas e praticamente voltadas para a construção de um ambiente interno e institucional favorável à governabilidade democrática. Os altos custos de informação, altos custos de decisão são característicos de ambientes em que há alta fricção institucional e cognitiva, resultando em baixa capacidade de agenda e baixa diversidade de temas prioritários. Não somente o tamanho e a baixa diversidade da agen- da mostram essa relação, como também os próprios assuntos que tomam conta das prioridades dos primeiros anos do governo Lula: governo e administração interna e macroeconomia. Ainda sobre a relação entre fricção e capacidade de agenda, a análise longitudinal mostra, de maneira clara, as mudanças incrementais e progressivas dentro dos governos do PT. A evolução temporal é marcada por aumento da capacidade de agenda, maior pluralidade de temas inseridos nas prioridades dos governos, ao passo que mais atores, mais problemas e mais proposições surgem na agenda governamental. Essa mudança somente pôde ocorrer com a construção de bases governistas, com a estabilização econômica e política, tanto no cenário doméstico, interno, quanto nas relações internacionais e na relação do Brasil com o mercado e a política intenacional.

A segunda conclusão que pode ser aferida a partir dos resultados encontrados está vinculada à análise transversal, na qual selecionamos alguns setores de políticas específicos para análise e compreensão do seu comportamento ao longo do tempo. Antes de adentrarmos as conclusões sobre esse tópico, é preciso pontuar que este trabaIho faz análises com um olhar mais macro, enxergando mudanças ou continuidades na atenção sobre políticas. Cada mudança, em cada política pública ou setor de política, demandaria uma análise pontual, via estudo de caso, com maior aprofundamento setorial. Aqui, nesse tipo de análise e lentes utilizadas, podemos tão somente indicar e caracterizar o comportamento das políticas, propondo estudos de caso futuros para compreender melhor o setor. De volta à segunda conclusão, selecionamos alguns casos de destaque encontrados nas análi- 
ses de dados para demonstrar o poder de eventos focalizados na mudança da atenção governamental: os casos da crise econômica internacional (2007-2010) e os eventos esportivos de grande porte (2014). O segundo ano do segundo governo Lula, 2008, é marcado por uma inflexão importante no comportamento da agenda. Nesse ano, há uma redução da capacidade da agenda, acompanhada de uma redução brusca na diversidade de temas prioritários para o presidente da República. A série histórica mostrava um crescimento constante de ambos os indicadores (capacidade e diversidade), mas, em 2008, há um padrão de cocnentração em assuntos sobre macroeconomia e política externa. Uma breve aproximação do período e dos dados demonstra que o fator causal dessa redução da agenda está relacionado com características do cenário econômico internacional, sobretudo pela crise global que durou de 2007 a 2011, mas que teve como pico os anos de 2008 e 2009. O crescente papel do Brasil no cenário econômico global e a crise que colocava em xeque grandes economias fizeram com que tal evento focalizado (crise) tivesse impacto direto nas prioridades da presidência. $\mathrm{O}$ mesmo ocorre com a ascensão abrupta das políticas de transporte no governo Dilma entre 2013 e 2014. Eventos focalizados como a aproximação de grandes eventos esportivos, como a Copa do Mundo de Futebol e os Jogos Olímpicos, que ocorreriam nos anos seguintes, alavancaram o assunto, que tinha baixa relevância nos anos anteriores, para as prioridades da presidente. Não podemos desconsiderar, também, o evento focalizado das Jornadas de Junho de 2013, que, com ações em diversas cidades do País, causou repercussão nacional e o aumento na atenção sobre questões de transporte.
A terceira e última conclusão está, portanto, relacionada a uma visão geral sobre os três governos do Partido dos Trabalhadores. De acordo com os dados mapeados e analisados, é possível concluir que mudanças nas prioridades dos governantes e mudanças na agenda governamental não ocorrem somente por mudanças macrossistêmicas, como a alteração de partidos políticos e seu espectro ideológico esquerda-centro-direita. Tais mudanças agem, certamente, nas prioridades e configurações da agenda governamental, mas isso não implica dizer que governos de mesmo partido, com os mesmos governantes ou com governantes distintos, possuem as mesmas prioridades e a mesma formatação de agenda. Fatores internos e externos constroem e descontroem bases aliadas, exigem respostas imediatas e rápida ascensão de temas às prioridades dos presidentes. Pautas internas, escolhas e trocas de ministros, desempenho econômico, relações com ambiente global, internacional, também são decisivos para a confuguração e mudanças nas prioridades presidenciais, muito além do partido político, mesmo que esse exerça algum grau de coesão aos governos analisados.

Em estudos futuros, pretende-se combinar os resultados a outros indicadores de atenção do Poder Executivo e de outros atores do sistema político. O método utilizado permite ampliar a série histórica da análise, o que permitirá observar padrões de continuidade ou ruptura em relação às políticas nas agendas dos diferentes governos. Análises comparativas entre a atenção do governo brasileiro a políticas específicas e as prioridades atribuídas por outros governos nacionais podem ser realizadas, tomando como parâme- 
tro estudos semelhantes. Os dados gerados na pesquisa poderão ser combinados com outros indicadores de atenção, em estudos posteriores, sendo empregados para analisar casos específicos ou mudanças no padrão de atenção em séries temporais.

\section{REFERÊNCIAS}

Arnold, C., Doyle, D., \& Wiesehomeier, N. (2017). Presidents, policy compromise, and legislative success. The Journal of Politics, 79(2), 380-395. doi:10.1086/688080

Baumgartner, F. R., Green-Pedersen, C., \& Jones, B. D. (2006). Comparative studies of policy agendas. Journal of European Public Policy, 13(7), 959-974. doi:10.1080/13501760600923805

Baumgartner, F. R., \& Jones, B. (Eds.). (2002). Policy dynamics. Chicago, USA: University of Chicago Press.

Baumgartner, F. R., \& Jones, B. D. (1993). Agendas and instability in American politics. Chicago, IL: University of Chicago Press.

Baumgartner, F. R., \& Jones, B. D. (2015). The politics of information: Problem definition and the course of public policy in America. Chicago, IL: University of Chicago Press.

Baumgartner, F. R., Jones, B. D., \& Macleod, M. C. (1998). Lessons from the trenches: Ensuring quality, reliability, and usability in the creation of a new data source. The Political Methodologist, 8(2), 1-10.

Baumgartner, F. R., Jones, B. D., \& Mortensen, P. B. (2014). Punctuated equilibrium theory: Explaining stability and change in public policymaking. In P. A. Sabatier, \& C. M. Weible (Eds.), Theories of the policy process (3rd. ed., pp. 155-188). Oxford, UK: Westview Press.

Baumgartner, F. R., Jones, B. D., \& Wilkerson, J. D. (2011). Comparative studies of policy dynamics. Comparative Political Studies, 44(8), 947-972. doi:10.1177/0010414011405160

Bevan, S. (2014). Gone fishing: The creation of the comparative agendas project master codebook. Recuperado de http://sbevan. com/cap-master-codebook.html

Brasil, F. G. (2017). A dinâmica das políticas de saúde e de assistência social no Brasil: Incrementalismo e pontuações na atenção governamental entre 1986 e 2003 (Tese de Doutorado, Universidade Federal de São Carlos, São Carlos, SP).

Capella, A. C. N. (2007). Perspectivas teóricas sobre o processo de formulação de políticas públicas. In G. Hochman, M. Arretche, \& E. Marques (Orgs.), Políticas públicas no Brasil. Rio de Janeiro, RJ: Fiocruz.

Capella, A. C. N., \& Brasil, F. G. (2015). A dinâmica das políticas públicas: Agendas governamentais em perspectiva comparada. I Encontro Nacional de Ensino e Pesquisa do Campo de Públicas (ENEPCP). Brasília, DF.

Capella, A. C. N., Brasil, F. G., \& Sudano, A. C. P. G. (2015). O estudo da agenda governamental: Reflexões metodológicas e indicativos para pesquisas. $39^{a}$ Encontro Anual da Anpocs. Caxambu, MG. Recuperado de http://www.anpocs.com/index.php/ papers-39-encontro/gt/gt30/9723-o-estudo-da-agenda-governamental-reflexoes-meto- 
dologicas-e-indicativos-para-pesquisas/file

Chaqués-Bonafont, L., Baumgartner, F. R. \& Palau, A.M. (2015). Agenda Dynamics in Spain. New York, NY: Palgrave MacMillan.

Cobb, R. W., \& Elder, C. D. (1971). The politics of agenda-building: An alternative perspective for modern democratic theory. Journal of Politics, 33(4), 892-915. doi:10.2307/2128415

Cobb, R. W., \& Elder, C. D. (1972). Participation in American politics: The dynamics of agenda building. Boston, MA: Allyn and Bancon.

Green-Pedersen, C. (2007). The growing importance of issue competition: The changing nature of party competition in Western Europe. Political studies, 55(3), 607-628. doi:10.1111/j.1467-9248.2007.00686.x

John, P. (2006). The policy agendas project: A review. Journal of European Public Policy, 13(7), 975-986. doi:10.1080/13501760600923870

Jones, B. D., \& Baumgartner, F. R. (2005). The politics of attention: How government priorizes problems. Chicago, IL: University of Chicago Press.

Jones, B. D., \& Baumgartner, F. R. (2012). From there to here: Punctuated equilibrium to the general punctuation thesis to a theory of government information processing. Policy Studies Journal, 40(1), 1-20. doi:10.1111/ j.1541-0072.2011.00431.x

Kingdon, J. (2003). Agendas, alternatives, and public policies (3rd ed.). New York, NY: Harper Collins.

True, J. J., Baumgartner, F. R., \& Jones, B. D. (1999). Punctuated-equilibrium theory: Explaining stability and change in American policymaking. In P. A. Sabatier (Eds.), Theories of the policy process (pp. 97-116). Oxford, UK: Westview Press.

Zahariadis, N. (2014). Ambiguity and multiple streams. In P. A. Sabatier, \& C. M. Weible, (Eds.), Theories of the policy process (3rd ed., pp. 65-92). Oxford, UK: Westview Press.

Zahariadis, N. (Org.). (2016). Handbook of public policy agenda setting. Cheltenham, Northapton, UK: Edward Elgar. 